ARTICLE

DOI: $10.1038 / s 41467-017-02084-0$

\title{
The anthelmintic praziquantel is a human serotoninergic G-protein-coupled receptor ligand
}

\author{
John D. Chan', Pauline M. Cupit ${ }^{2}$, Gihan S. Gunaratne ${ }^{1}$, John D. McCorvy ${ }^{3}$, Yang Yang (1) ${ }^{1}$, Kristen Stoltz ${ }^{4}$
} Thomas R. Webb ${ }^{5}$, Peter I. Dosa ${ }^{4}$, Bryan L. Roth ${ }^{3,6,7}$, Ruben Abagyan², Charles Cunningham ${ }^{8}$

$\&$ Jonathan S. Marchant $1,9,10$

Schistosomiasis is a debilitating tropical disease caused by infection with parasitic blood flukes. Approximately 260 million people are infected worldwide, underscoring the clinical and socioeconomic impact of this chronic infection. Schistosomiasis is treated with the drug praziquantel (PZQ), which has proved the therapeutic mainstay for over three decades of clinical use. However, the molecular target(s) of $P Z Q$ remain undefined. Here we identify a molecular target for the antischistosomal eutomer - $(R)-P Z Q-$ which functions as a partial agonist of the human serotoninergic $5 \mathrm{HT}_{2 \mathrm{~B}}$ receptor. $(R)-\mathrm{PZQ}$ modulation of serotoninergic signaling occurs over a concentration range sufficient to regulate vascular tone of the mesenteric blood vessels where the adult parasites reside within their host. These data establish (R)-PZQ as a G-protein-coupled receptor ligand and suggest that the efficacy of this clinically important anthelmintic is supported by a broad, cross species polypharmacology with $\mathrm{PZQ}$ modulating signaling events in both host and parasite.

\footnotetext{
${ }^{1}$ Department of Pharmacology, University of Minnesota, Minneapolis, MN 55455, USA. ${ }^{2}$ Skaggs School of Pharmacy and Pharmaceutical Sciences, University of California San Diego, La Jolla, CA 92093, USA. ${ }^{3}$ Department of Pharmacology, University of North Carolina at Chapel Hill, Chapel Hill, NC 27599-7365, USA. ${ }^{4}$ Institute for Therapeutics Discovery and Development, University of Minnesota, Minneapolis, MN 55414, USA. ${ }^{5}$ Division of Biosciences, SRI International, Menlo Park, CA 94025, USA. ${ }^{6}$ Division of Chemical Biology and Medicinal Chemistry, Eshelmann School of Pharmacy, University of North Carolina at Chapel Hill, Chapel Hill, NC 27599-7360, USA. ${ }^{7}$ National Institute of Mental Health Psychoactive Drug Screening Program (NIMH PDSP), School of Medicine, University of North Carolina at Chapel Hill, Chapel Hill, NC 27599-7360, USA. ${ }^{8}$ Department of Biology, University of New Mexico,

Albuquerque, NM 87131, USA. ${ }^{9}$ Stem Cell Institute, University of Minnesota, Minneapolis, MN 55455, USA. ${ }^{10}$ Department of Cell Biology, Neurobiology and Anatomy, Medical College of Wisconsin, Milwaukee, WI 53226, USA. John D. Chan, Pauline M. Cupit, Gihan S. Gunaratne and John D. McCorvy contributed equally to this work. Correspondence and requests for materials should be addressed to J.S.M. (email: jmarchant@mcw.edu)
} 
undreds of millions of people are infected with parasitic worms $^{1}$. One of the most burdensome infections is the neglected tropical disease schistosomiasis (Bilharzia) caused by parasitic flatworms of the genus Schistosoma ${ }^{2}$. Schistosoma infections result from contact with fresh water containing cercariae, the free-swimming larval stage of the parasite. Cercariae penetrate the host's skin, and then transform and mature into sexualized forms while undergoing a remarkable intravascular migration to defined vascular beds, where paired male and female worms complete their maturation and commence egg laying ${ }^{2,3}$. a<smiles>O=C(C1CCCCC1)N1CC(=O)N2CCc3ccccc3[C@H]2C1</smiles>

(R)-PZQ

b<smiles>O=C(C1CCCCC1)N1CC(=O)N2CCc3ccccc3[C@H]2C1</smiles>

(S)-PZQ
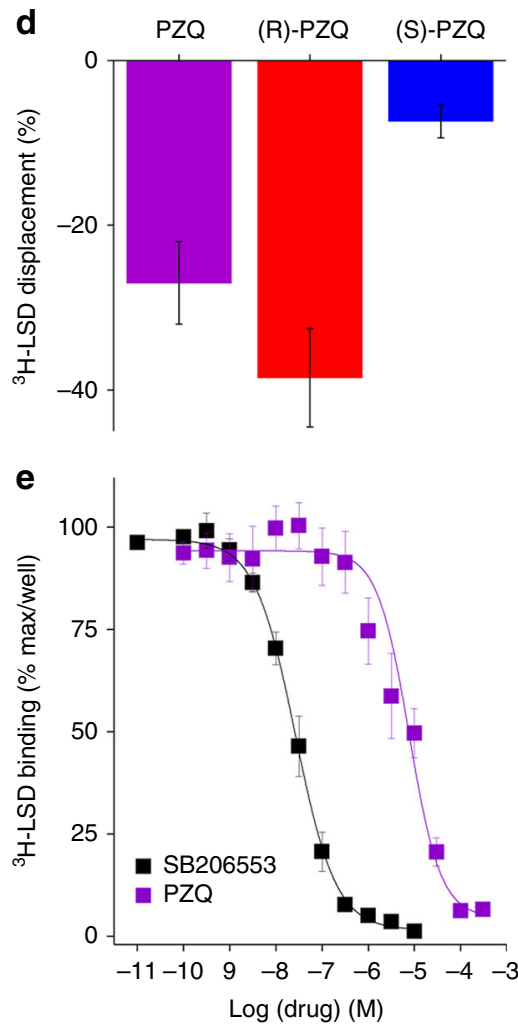

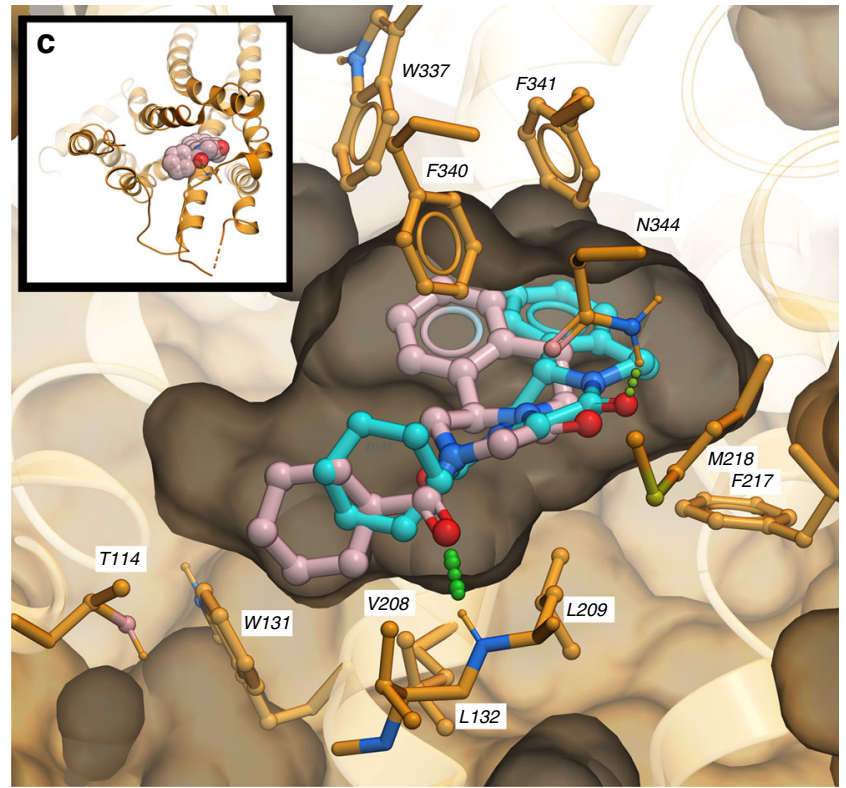

f
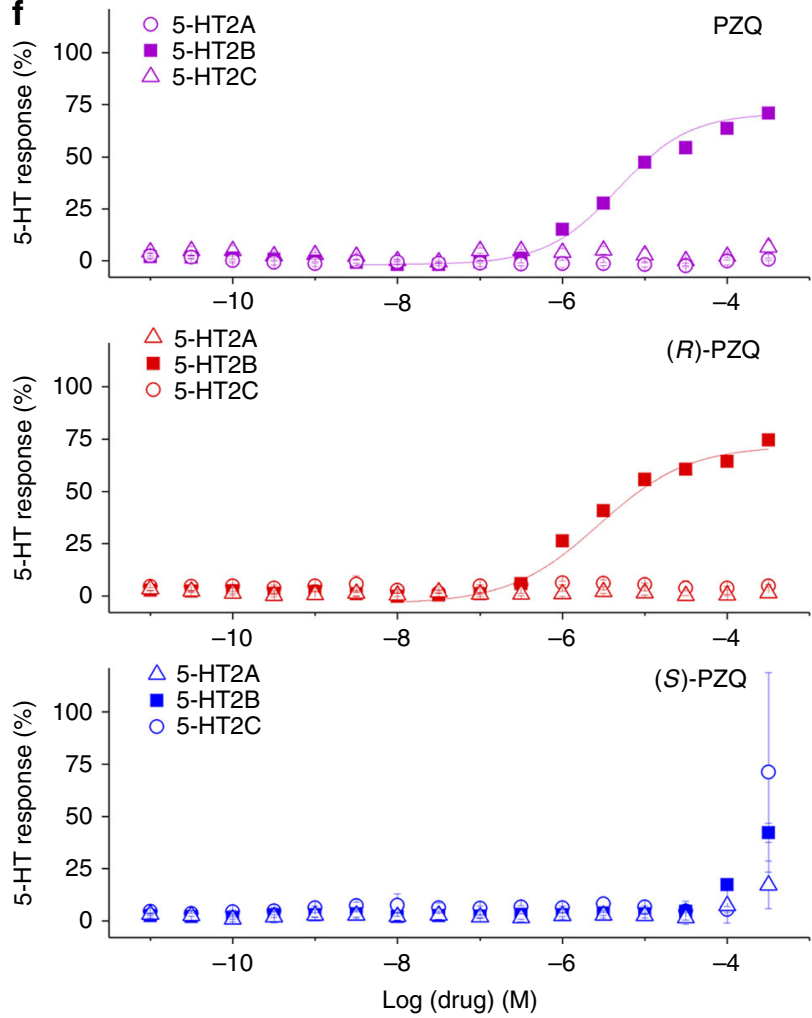

Fig. 1 Resolution of stereoselective (R)-PZQ interaction with human $5-\mathrm{HT}_{2 \mathrm{~B}} \mathrm{R}$. Structures of the PZQ enantiomers: active, a antischistocidal (R)-PZQ (top, red) and $\mathbf{b}(S)-P Z Q$ (bottom, blue). c Docking poses of R-PZQ (light red) and S-PZQ (light blue) in the human $5 H_{2} T_{2}$. Both isomers of PZQ dock favorably within the orthosteric pocket of the $5 \mathrm{HT}_{2 \mathrm{~B}} \mathrm{R}$ crystal structure (Protein Databank Code: $5 \mathrm{TVN}$ ). The R-isomer shows a better predicted binding score by $0.6 \mathrm{kcal} /$ mole partially due to a more favorable hydrogen bond with the backbone $\mathrm{NH}$ group of L209. $\mathbf{d}$ Displacement of ${ }^{3} \mathrm{H}-\mathrm{LSD}$ binding at human $5-\mathrm{HT}{ }_{2 B} \mathrm{R}$ by racemic PZQ $(( \pm)-P Z Q 10 \mu \mathrm{M}$, purple), (R)-PZQ $(5 \mu \mathrm{M}$, red) and (S)-PZQ ( $5 \mu \mathrm{M}$, blue) in the PDSP primary screen ( $n=5$ for all measurements). e Complete binding displacement curves for ${ }^{3} \mathrm{H}$-LSD displacement at human $5-\mathrm{HT}_{2 \mathrm{~B}} \mathrm{R}$ for SB206553 (black) and ( \pm )-PZQ (purple, $n=5$ for both ligands). f Functional Assays. $\mathrm{Ca}^{2+}$ flux assays showing responses from fluo-4 loaded Flp-In T-REx cells stably expressing 5- $\mathrm{HT}_{2 \mathrm{~A}} \mathrm{R}, 5-\mathrm{HT}_{2 B} \mathrm{R}$, or $5-\mathrm{HT} \mathrm{T}_{2 \mathrm{C}} \mathrm{R}$ at indicated concentrations of ( \pm )-PZQ (purple, top), ( $R$ )-PZQ (red, middle) and (S)-PZQ (blue, bottom; $n=3$ for each concentration) in cells expressing $5-\mathrm{HT}_{2 \mathrm{~A}} \mathrm{R}, 5-\mathrm{HT}_{2 B} \mathrm{R}$, or $5-\mathrm{HT}_{2 \mathrm{C}} \mathrm{R}$ 
a
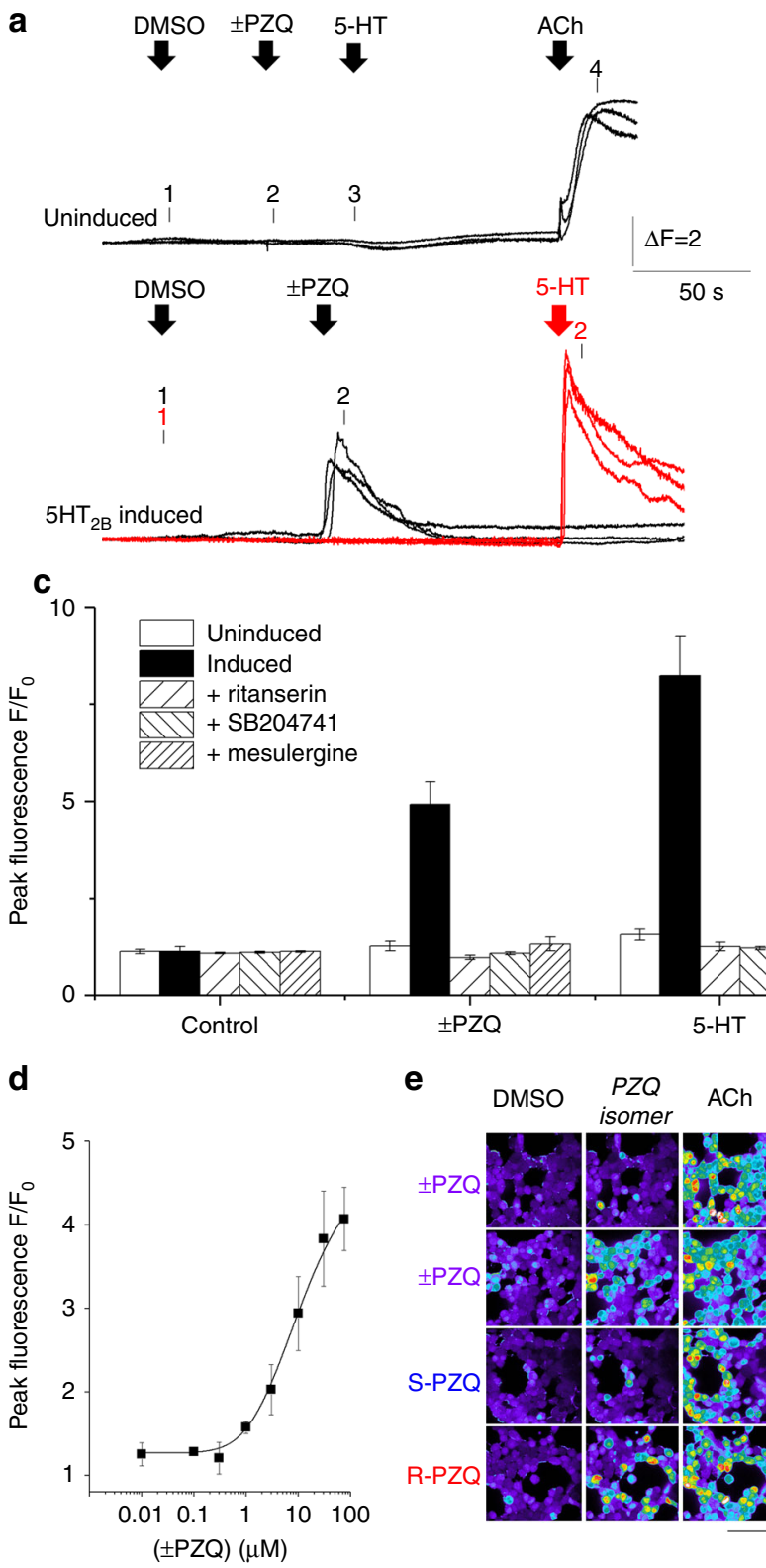

d

$( \pm \mathrm{PZQ})(\mu \mathrm{M})$ b

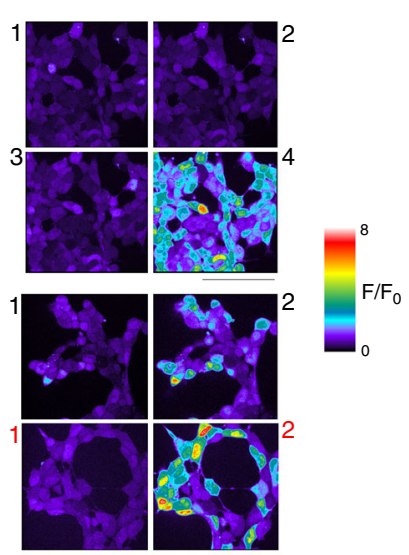

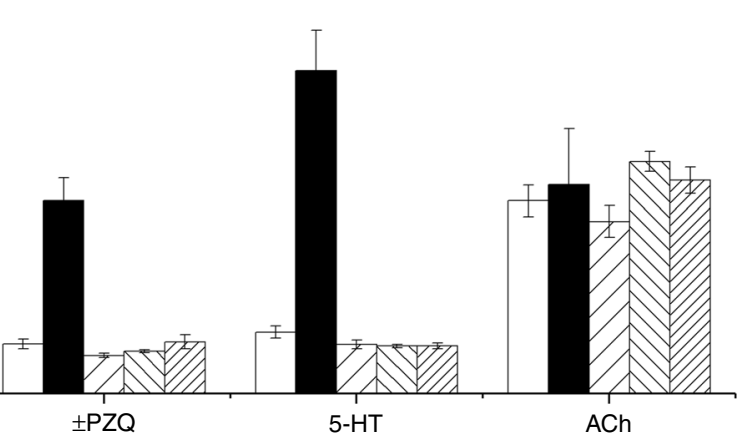

e

e DMSO
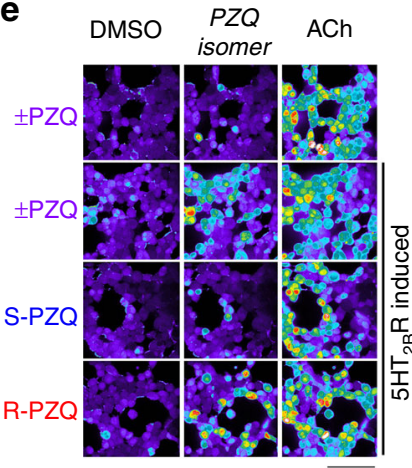

f

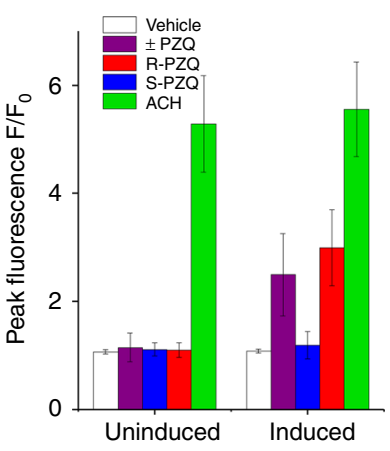

Fig. 2 (R)-PZQ triggers $\mathrm{Ca}^{2+}$ release via $5-\mathrm{HT}_{2 B} \mathrm{R}$. a Representative fluorescence traces from a single experiment where single cells loaded with fluo-4-AM in a HEK293 cell line prior to (top), or after (bottom) $5-\mathrm{HT}_{2 B} \mathrm{R}$ induction. Traces show fluorescence ratio following addition of indicated ligands (final concentrations $( \pm)$-PZQ $(75 \mu M), 5-H T(100 \mathrm{nM})$ or ACh $(100 \mu \mathrm{M})$ ), or vehicle (DMSO, 0.05\%). b Pseudocolored confocal images are displayed from the indicated times ('1'-' 4 ') on associated fluorescence traces as introduced in Fig. 1a. Scalebar, $80 \mu \mathrm{m}$. c Peak fluorescence ratio $\left(F / F_{0}\right.$, where ' $F$ ' represents fluorescence at peak and ' $\mathrm{F}_{\mathrm{O}}$ ' represents fluorescence at time $=0$ ) from cumulative $\mathrm{Ca}^{2+}$ imaging after addition of vehicle, $( \pm)-\mathrm{PZQ}, 5-\mathrm{HT}$ or $\mathrm{ACh}$ in uninduced (open bars) or induced cell lines (solid, hatched bars; $n \geq 3$ independent inductions). Serotonergic antagonists (ritanserin (100 nM, final concentration), SB204741 (100 nM), or mesulergine (200 nM) were preincubated with induced cells prior to addition of ( \pm )-PZQ (75 $\mu M)$, 5-HT (10 nM), or ACh $(100 \mu \mathrm{M})$. Data represent means \pm s.e.m. of peak responses averaged from multiple cells $(>20)$ from $n \geq 3$ independent inductions. d Doseresponse relationship for ( \pm )-PZQ efficacy in cells induced for $5-\mathrm{HT}_{2 \mathrm{~B}} \mathrm{R}$ expression ( $n=6$ for each concentration). e Confocal Ca ${ }^{2+}$ imaging assays with $( \pm)-P Z Q$ and resolved enantiomers in uninduced (top row) and $5-\mathrm{HT}_{2 \mathrm{~B}} \mathrm{R}$ induced cell lines (bottom three rows). Experiments were performed with racemic PZQ ( $( \pm)-P Z Q)$, and individual (S)-PZQ and (R)-PZQ stereoisomers $(5 \mu \mathrm{M}$, final concentration). Scalebar, $80 \mu \mathrm{m}$. f Processed data set from experiments such as shown in e representing population mean \pm s.e.m. ( $>20$ cells) from $n \geq 3$ independent inductions

The debilitating impact of schistosomiasis results from the host's immune response to schistosome eggs, deposited in prolific numbers in the liver, intestine and/or bladder where they elicit granulomatous inflammation, periportal fibrosis and hypertension $^{2}$. Clinical outcomes span gastrointestinal and liver pathologies, genitourinary disease, anemia, malnutrition, and a heightened risk for comorbidities and HIV transmission. The associated disease burden encumbers third world economies with an annual loss of up to 70 million disability-adjusted life years ${ }^{4,5}$.
Effective drug therapy for schistosomiasis is therefore a key healthcare priority.

Praziquantel, a tetracyclic tetrahydroisoquinoline derivative administered as a racemic mixture $(( \pm)-P Z Q)$, is the main drug therapy for combating schistosomiasis. PZQ causes rapid paralysis of schistosome musculature and subsequent tegumental damage that promotes immunological clearance of worms from the host. The World Health Organization estimates a considerable future demand for PZQ of 2 billion tablets over 5 years to 
a

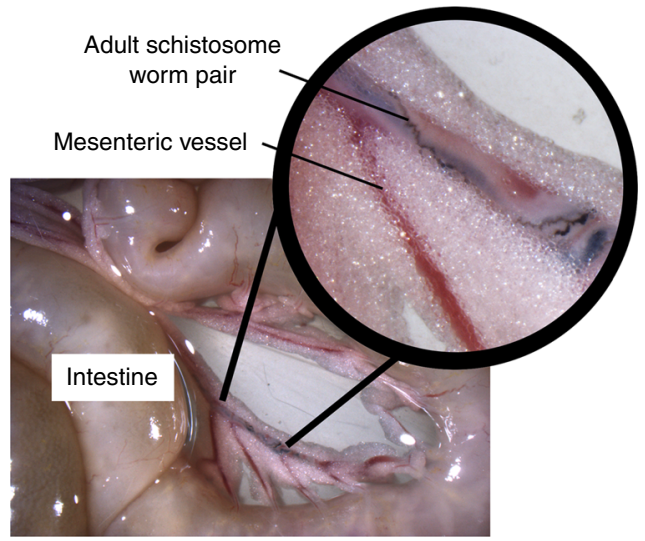

b

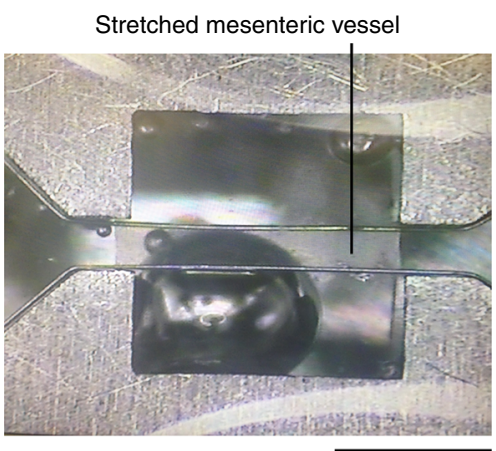

C
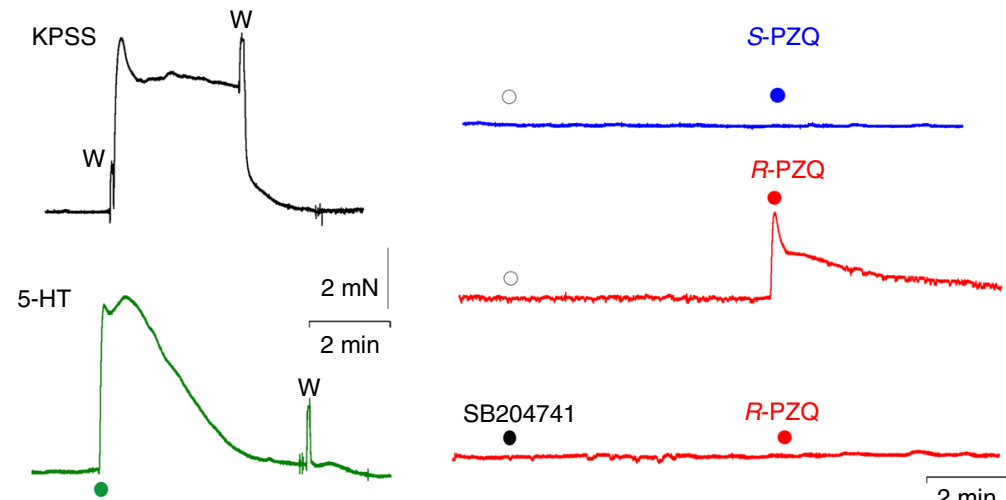

-

d

e
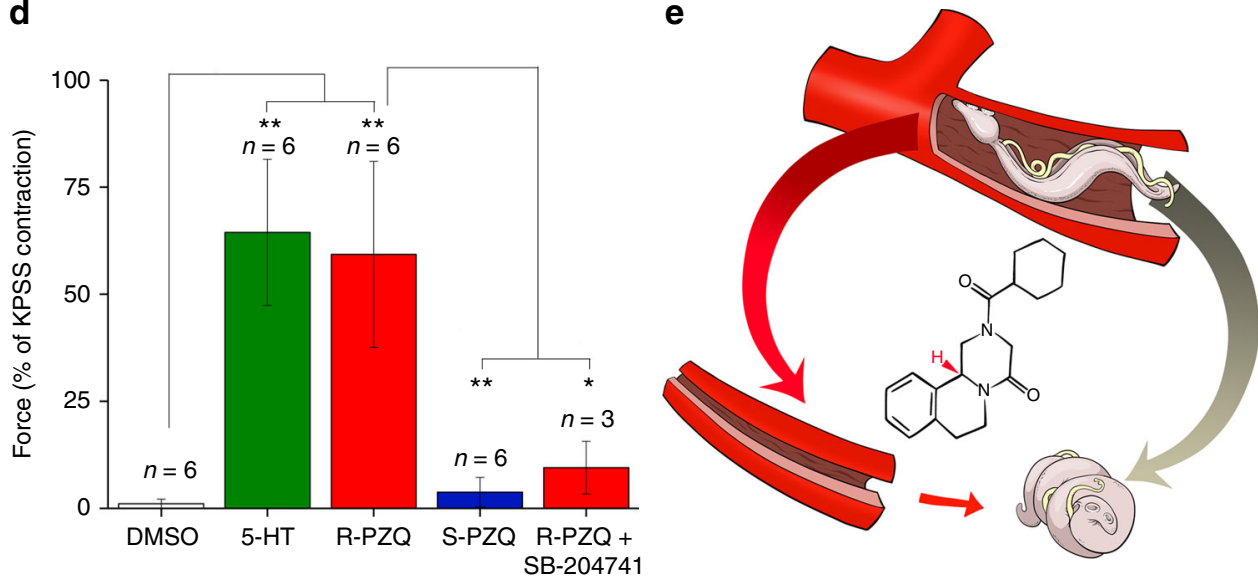

Fig. 3 (R)-PZQ constricts mouse mesenteric vasculature. a Image of mesentery surrounding mouse intestine, showing blood vessel containing a schistosome worm-pair (inset). b Representative image of a surgically isolated piece of mouse mesenteric artery held under tension between two clamped wires. Scalebar, $1 \mathrm{~mm}$. c Changes in tension triggered by varied manipulations. Left, sustained contraction of vessels in KPSS and 5-HT (10 $\mu$ M). Right, tension in individual arteries incubated in the presence of vehicle (DMSO, open circle) or SB204741 (10 $\mu$ M, closed circle), and challenged with ( $R$ )-PZQ $(50 \mu \mathrm{M})$ or $(S)-P Z Q(50 \mu M)$. W, wash; complete media exchange. Preincubation of strips with SB204741 (10 $\mu M)$ attenuated (R)-PZQ evoked vasoconstriction. $\mathbf{d}$ Cumulative data set from experiments reporting effects of ligands relative to KPS(S)-evoked contractile tension, concentrations of ligands: 5-HT $(1 \mu \mathrm{M}),(R)-\mathrm{PZQ}(50 \mu \mathrm{M}),(\mathrm{S})-\mathrm{PZQ}(50 \mu \mathrm{M})$, SB204741 $(10 \mu \mathrm{M})$. Replicate number for each measurement as indicated, where individual measurements reflect the response from a naïve artery isolated from different mice. Data are presented as mean \pm s.d. Probability, $p<0.05\left({ }^{*}\right), p<0.01$ $\left.{ }^{(\star}\right)$. e Schematic model (not to scale) depicting ( $R$ )-PZQ action on both parasite (contraction) and host vasculature (contraction, increased perfusion pressure) facilitating hepatic shift of worms

support mass drug administration initiatives ${ }^{5}$. Clearly, the continued efficacy of PZQ is essential for this strategy and reports of PZQ-resistant worm isolates in both laboratory and field highlight an urgency in resolving how PZQ works ${ }^{6-8}$. Such knowledge would catalyze the development of next generation anthelmintics. Here we employ a variety of experimental approaches to demonstrate that the antischistosomal eutomer $(R)$-PZQ acts as a partial agonist of the human $5-\mathrm{HT}_{2 \mathrm{~B}}$ receptor, establishing $(R)$ -
PZQ as a GPCR ligand. These data will prioritize future screening of flatworm GPCRs for a (R)-PZQ target and underscore an activity of (R)-PZQ on $5-\mathrm{HT}_{2 \mathrm{~B}} \mathrm{R}$ signaling in the human host, manifest within the vascular beds where the adult parasites reside.

\section{Results}

Mammalian GPCR target(s) of PZQ. Prior work has demonstrated an ergomimetic like action of PZQ to engage flatworm 
bioaminergic signaling pathways ${ }^{9}$. Specifically, PZQ exposure caused a bipolar regeneration phenotype in regenerating freeliving planarian flatworms that was phenocopied by ergot alkaloids acting as serotonergic antagonists, but opposed by 5 hydroxytryptamine $\left(5-\mathrm{HT}^{9}\right)$. Similarly, in both adult schistosome worms (Supplementary Fig. 1) and schistosomules ${ }^{9}$, PZQ evoked a rapid paralysis counteracted by exogenous $5-\mathrm{HT}$. On the basis of these observations, we considered whether PZQ acts as a direct serotoninergic ligand to oppose 5-HT evoked G-protein-coupled receptor (GPCR) signaling.

To investigate the possibility that $\mathrm{PZQ}$ engages serotoninergic GPCRs, in silico docking approaches were first applied. The resolved PZQ enantiomers- $(R)-\mathrm{PZQ}$ (the active, antischistocidal eutomer, Fig. 1a) and (S)-PZQ (Fig. 1b) - were screened against a panel of 3436 computational models, representing 1465 protein targets mostly of human origin, ('MolScreen'). Both ligands were docked and scored into ensemble $4 \mathrm{D}^{10}$ models of various targets assembled in the Pocketome database ${ }^{11}$. The top candidate from the docking to pocket classification ('dpc' models) was the human $5-\mathrm{HT}_{2 \mathrm{~B}}$ receptor $\left(5-\mathrm{HT}_{2 \mathrm{~B}} \mathrm{R}\right)$, with $(R)-\mathrm{PZQ}$ possessing the highest predicted affinity (Supplementary Table 1). Figure 1c depicts the orientation of both $(R)-\mathrm{PZQ}$ and (S)-PZQ within the $5-\mathrm{HT}_{2 \mathrm{~B}} \mathrm{R}$ orthosteric binding pocket from modeling simulations. Different binding orientations for both PZQ enantiomers were predicted with the $(R)$-isomer exhibiting a more favorable hydrogen bond with the backbone amine group of $\mathrm{L} 209$ in extracellular loop 2 of $5-\mathrm{HT}_{2 \mathrm{~B}} \mathrm{R}$ (Fig. 1c).

With these in silico predictions in hand, we profiled a broad panel of human GPCRs through the NIMH Psychoactive Drug Screening Program $\left(\mathrm{PDSP}^{12}\right)$ first using racemic $( \pm)-\mathrm{PZQ}(10$ $\mu \mathrm{M})$ and then the resolved enantiomers ( $(R)-\mathrm{PZQ}$ and $(S)-\mathrm{PZQ}^{13}$; Supplementary Fig. 2). ( \pm )-PZQ exhibited a polypharmacological profile (Supplementary Fig. 3) consistent with predictions from the in silico modeling data (Fig. 1b). The ability of PZQ to engage host GPCRs likely explains prior reports of $( \pm)$-PZQ action on heart and smooth muscle ${ }^{14,15}$, and potentially other known activities of PZQ such as the bitterness of $(S)-\mathrm{PZQ}^{16}$, a taste transduced through GPCR signaling. This screen was then repeated using the individual enantiomers with the criterion for a positive screening hit defined as stereoselective inhibition of radioligand binding by (R)-PZQ, but not (S)-PZQ. This was observed at only one GPCR in the primary screen-the human 5$\mathrm{HT}_{2 \mathrm{~B}}$ receptor $\left(5-\mathrm{HT}_{2 \mathrm{~B}} \mathrm{R}\right)$ - where inhibition seen with $( \pm)-\mathrm{PZQ}$ was attributable solely to (R)-PZQ (Fig. 1d, Supplementary Fig. 3). These data support the in silico modeling, although demonstrate more biological selectivity for (R)-PZQ over (S)-PZQ at $5-\mathrm{HT}_{2 \mathrm{~B}} \mathrm{R}$.

PZQ interaction with $5-\mathrm{HT}_{2 \mathrm{~B}} \mathrm{R}$ was then validated using radioligand binding and functional assays. Analysis of $\left[{ }^{3} \mathrm{H}\right]-\mathrm{LSD}$ displacement by $( \pm)-\mathrm{PZQ}$ revealed complete displacement of specific $\left[{ }^{3} \mathrm{H}\right]$-LSD binding at $5-\mathrm{HT}_{2 \mathrm{~B}} \mathrm{R}$ by unlabeled $( \pm)$-PZQ $\left(K_{\mathrm{i}}\right.$ $=5.3 \mu \mathrm{M}$, Fig. 1e). For functional activity, $\mathrm{Ca}^{2+}$ flux assays were performed in HEK293 cells expressing individual $5 \mathrm{HT}_{2} \mathrm{R}$ isoforms. (R)-PZQ evoked $\mathrm{Ca}^{2+}$ release in $5-\mathrm{HT}_{2 \mathrm{~B}} \mathrm{R}$ expressing cells at concentrations $>1 \mu \mathrm{M}$ (Fig. 1f). The peak amplitude of (R)-PZQevoked $\mathrm{Ca}^{2+}$ release was consistently less than evoked by $5-\mathrm{HT}$ (Fig. 1d), suggesting action as a $5-\mathrm{HT}_{2 \mathrm{~B}} \mathrm{R}$ partial agonist. No $\mathrm{Ca}^{2+}$ release activity was observed using (S)-PZQ over a comparable concentration range (Fig. 1f). No $\mathrm{Ca}^{2+}$ release activity was observed in uninduced cells lacking $5-\mathrm{HT}_{2 \mathrm{~B}} \mathrm{R}$ expression, or cells expressing either $5-\mathrm{HT}_{2 \mathrm{~A}} \mathrm{R}$ or $5-\mathrm{HT}_{2 \mathrm{C}} \mathrm{R}$ (Fig. 1f), indicating that (R)-PZQ activity was specific and selective for the $5-\mathrm{HT}_{2 \mathrm{~B}} \mathrm{R}$. At other tested GPCRs, including several predicted by the modeling simulations (Supplementary Table 1), ( \pm )-PZQ lacked $\mathrm{Ca}^{2+}$ release activity (Supplementary Fig. 4).

Further characterization of PZQ-evoked $\mathrm{Ca}^{2+}$ release was performed in a $5-\mathrm{HT}_{2 \mathrm{~B}} \mathrm{R}$ inducible cell line by confocal imaging. Neither $( \pm)-\mathrm{PZQ}$, nor 5-HT, evoked cellular $\mathrm{Ca}^{2+}$ transients in the absence of $5-\mathrm{HT}_{2 \mathrm{~B}} \mathrm{R}$ induction, whereas acetylcholine (ACh) elevated cytoplasmic $\mathrm{Ca}^{2+}$ through endogenous GPCRs (Fig. 2a, b). Following $5-\mathrm{HT}_{2 \mathrm{~B}} \mathrm{R}$ induction, both $( \pm)-\mathrm{PZQ}$ and $5-\mathrm{HT}$ triggered $\mathrm{Ca}^{2+}$ signals (Fig. 2a, b). Prior incubation of induced cells with serotonergic blockers ritanserin, SB2047471, or mesulergine blocked PZQ and 5-HT evoked $\mathrm{Ca}^{2+}$ transients, but failed to impact ACh-evoked $\mathrm{Ca}^{2+}$ signals (Fig. 2c). Doseresponse relationships revealed $( \pm)-\mathrm{PZQ}$ activity over the micromolar range $\left(\mathrm{EC}_{50}=8.1 \mu \mathrm{M}\right.$; Fig. $\left.2 \mathrm{~d}\right)$ with $\mathrm{Ca}^{2+}$ release activity solely caused by the (R)-enantiomer (Fig. 2e, f). The 5$\mathrm{HT}_{2 \mathrm{~B}} \mathrm{R}$ blocker LY272015 also inhibited PZQ-evoked $\mathrm{Ca}^{2+}$ signals (Supplementary Fig. 5).

Next, we examined PZQ-evoked signaling using a transcriptional reporter assay, designed to monitor $\mathrm{Ca}^{2+}$-dependent NFAT translocation (Supplementary Fig. 6A). In HEK293 cells expressing the reporter construct alone, neither $( \pm)$-PZQ nor 5-HT increased the basal luminescence signal (Supplementary Fig. 6B). In cells transiently transfected with $5-\mathrm{HT}_{2 \mathrm{~B}} \mathrm{R}$, both PZQ and 5-HT elicited NFAT translocation and this response was blocked by ritanserin (Supplementary Fig. 6B). (R)-PZQ activation of NFAT occurred over the micromolar range (Supplementary Fig. 6C), again less potent and penetrant than observed with 5-HT (Figs. 1d, 2d). Therefore, multiple experimental approaches demonstrated (R)-PZQ acted as a partial agonist at human $5-\mathrm{HT}_{2 \mathrm{~B}} \mathrm{R}$.

Action of (R)-PZQ at host GPCRs. These data are significant for two reasons. First they identify PZQ as a bona fide GPCR ligand at a defined molecular target. This discovery prioritizes future screening of flatworm GPCRs ( 120 GPCRs in schistosomes $\left.{ }^{17}\right)$ for a receptor selectively engaged by $(R)-\mathrm{PZQ}$ that could be a key target for future antischistosomal drug development ${ }^{18,19}$. Second, these data suggest $\mathrm{PZQ}$ - conventionally viewed as a selective antiparasitic therapy-can interact with endogenous $5-\mathrm{HT}_{2 \mathrm{~B}} \mathrm{Rs}$ in the human host. One pathophysiologically relevant effect would be an activity of (R)-PZQ on host mesenteric vascular beds, a destination of the mature, paired adult S. mansoni and S. japonicum blood flukes and sites where egg laying commences ${ }^{2,3}$ (Fig. 3a). After drug treatment, worms are rapidly displaced from their mesenteric habitat to the liver where elimination occurs. This 'hepatic shift' is a frequently used assay for drug efficacy and has been attributed to loss of worm muscle tone evoked by antischistosomal agents ${ }^{20,21}$ as seen in vitro (Supplementary Movie 1). Serotonergic ligands are well known regulators of the tone of arteries and veins ${ }^{22,23}$, including mesenteric vessels ${ }^{23}$, such that PZQ-evoked changes in mesenteric blood flow may help 'flush' PZQ-paralyzed worms toward the liver. Levels of PZQ within the splanchnic vasculature likely reach levels an order of magnitude higher than peak plasma concentrations that are measured after first-pass metabolism of the drug $(>4 \mu \mathrm{M}$ for $40 \mathrm{mg} / \mathrm{kg}$ human dosing, even higher in mouse models ${ }^{24,25}$ ). Therefore, PZQ concentration within mesenteric vessels falls well within the concentration range for causing host serotonergic effects demonstrated in vitro (Figs. 1, 2).

The activity of PZQ within the mesenteric vasculature of uninfected mice was assessed by measuring mesenteric artery tone using wire myography. Mounted vessel segments (Fig. 3b) exhibited a rapid, sustained contraction to high $\mathrm{K}^{+}$media which reversed upon media exchange (Fig. 3c). Addition of 5-HT to resting vessel segments also elicited a protracted, contractile response that declined over time (Fig. 3c). Addition of (R)-PZQ to naive vessels mimicked the profile of 5 -HT evoked contractions (Fig. 3c), and this effect was prevented by preincubation with SB204741, a 5- $\mathrm{HT}_{2 \mathrm{~B}} \mathrm{R}$ antagonist (Fig. 3c). No changes in resting tone were observed with (S)-PZQ. PZQ also evoked contraction of hepatic portal vein segments (Supplementary Fig. 7), again 
mimicking 5-HT action ${ }^{26}$. The cumulative data set demonstrates (R)-PZQ caused mesenteric artery vasoconstriction, mimicking the action of 5-HT (Fig. 3d).

In conclusion, we demonstrate that PZQ is a GPCR ligand, with antischistocidal (R)-PZQ acting as a low micromolar affinity partial agonist at human $5-\mathrm{HT}_{2 \mathrm{~B}}$ receptors. Activity at both parasite and host receptors-both targets potentially being GPCRs-likely contributes to clinical efficacy of PZQ by combining a deleterious paralytic effect on the parasite (Supplementary Movie 1) with beneficial host effects that promote worm clearance. We propose PZQ causes contraction of both the parasite and host mesenteric vessels to increase perfusion pressure and flush paralyzed worms to the liver (Fig. 3e). PZQ activity at host $5-\mathrm{HT}_{2 \mathrm{~B}} \mathrm{Rs}$ may be further enhanced in individuals infected with chronic schistosomiasis where pathological changes slow drug elimination ${ }^{24}$, heighten serotonergic sensitivity ${ }^{26}$ and lower basal arteriolar resistance ${ }^{27}$. Further, the beneficial effects of host GPCR engagement may extend beyond the vasculature given a role for $5 \mathrm{HT}_{2 \mathrm{~B}} \mathrm{Rs}$ in regulating inflammation, liver fibrosis and regeneration: all outcomes relevant to chronic schistosomiasis pathology ${ }^{28,29}$. In conclusion, these data support a strategy for developing novel anthelmintics with cross species polypharmacology to reinforce disease mitigating actions in both host and parasite.

\section{Methods}

Reagents. Ritanserin, SB204741 and mesulergine were from Tocris Bioscience. All other ligands were from Sigma-Aldrich. Cell culture reagents were from Invitrogen. PZQ enantiomers $((R)-[-] \mathrm{PZQ}$ and $(S)-[+] \mathrm{PZQ})$ were resolved (Supplementary Fig. 2) using methods published by Woelfle et al. ${ }^{13}$.

\section{Mammalian GPCR profiling. PZQ (racemic and enantiomers) were screened} against human GPCRs using primary and secondary assays coordinated through the NIMH Psychoactive Drug Screening Program (PDSP). Full details describing these methods are available in the PDSP Assay Protocol Book available online (https:// pdspdb.unc.edu/pdspWeb/). PZQ was dissolved in $100 \%$ ethanol at a concentration of $100 \mathrm{mM}$ to achieve a maximal assay concentration (up to $100 \mu \mathrm{M}$ ) for both binding and functional assays. $\mathrm{Ca}^{2+}$ flux experiments utilized tetracycline-inducible stable cell lines for $5 \mathrm{HT}_{2 \mathrm{~A}}, 5 \mathrm{HT}_{2 \mathrm{~B}}$, and $5 \mathrm{HT}_{2 \mathrm{C}}$ receptors initially generated using the Flp-In 293 T-REx tetracycline inducible system ${ }^{30}$ (a gift from the Roth Lab, Invitrogen). Cells were maintained in DMEM (ThermoFisher, 10569010) supplemented with $10 \%$ dialyzed fetal bovine serum (Gibco, 26400044), $50 \mathrm{U} / \mathrm{mL}$ PenicillinStreptomycin (ThermoFisher Scientific, 15140122), $10 \mu \mathrm{g} / \mathrm{ml}$ Blasticidin (Research Products International, B12150-0.1) and $100 \mu \mathrm{g} / \mathrm{ml}$ Hygromycin B (ThermoFisher Scientific, 10687010) at $37^{\circ} \mathrm{C}$ and $5 \% \mathrm{CO}_{2}$. For $\mathrm{Ca}^{2+}$ flux assays, receptor expression was induced with $2 \mu \mathrm{g} / \mathrm{mL}$ tetracycline, and cells were plated into white 384 clear bottom, tissue culture plates in $40 \mu \mathrm{L}$ of DMEM containing $1 \%$ dialyzed FBS at a density of $\sim 15,000$ cells per well the day before the assay. Next day, media was decanted and $20 \mu \mathrm{L}$ per well of Fluo-4 Direct dye (Invitrogen) was added and incubated for $1 \mathrm{~h}$ at $37^{\circ} \mathrm{C}$. The cells were stimulated with test compounds diluted in drug buffer (HBSS, $20 \mathrm{mM}$ HEPES, $0.1 \%$ BSA, $0.01 \%$ ascorbic acid, $\mathrm{pH} 7.4$ ) and calcium flux was measured using a FLIPR TETRA (Molecular Devices). Plates were read for fluorescence initially for $10 \mathrm{~s}$ ( 1 read per second) to establish a baseline, and then stimulated with drug dilutions or buffer and read for an additional $110 \mathrm{~s}$. Peak fluorescence in each well was normalized to maximum-fold increase over baseline. The data were normalized to maximum peak fold over basal fluorescence by 5-HT $(100 \%)$ and baseline fluorescence $(0 \%)$. The data were analyzed using the sigmoidal dose-response function built into GraphPad Prism 5.0.

In silico modeling. (R)-PZQ and (S)-PZQ were screened against a panel of 3436 computational models designed to predict activities of arbitrary chemical compounds, representing 1465 proteins targets mostly of human origin (so called 'MolScreen' panel). The earlier version of this set of models that included different classes of targets ${ }^{31}$ described and validated the panel. Two main types of three dimensional docking models were used: 'dpc' models (349 models representing the conformational ensembles of binding pocket conformations from the Pocketome database ${ }^{11}$ ) and 'dfa' models (pharmacophoric field models based on the continuous three dimensional pharmacophoric fields of the diverse co-crystallized ligands from the Pocketome database, enhanced by training on the activity data from the $\mathrm{ChEmbl}$ database ${ }^{32,33}$ ).

Confocal $\mathrm{Ca}^{2+}$ imaging. For single-cell confocal $\mathrm{Ca}^{2+}$ imaging, the $5 \mathrm{HT}_{2 \mathrm{~B}}$ inducible cell line was seeded onto collagen-coated, $35 \mathrm{~mm}$ glass bottom dishes (MatTek, P35GCOL-0-14-C) at a density of $1 \times 10^{4}$ cells three days prior to imaging. Two days prior to imaging, 5-HT receptor expression was induced by supplementing the growth media with $1 \mu \mathrm{g} / \mathrm{ml}$ doxycycline (Sigma-Aldrich, D3447). Two hours prior to conducting experiments, growth medium was exchanged for EMEM supplemented with 1\% dialyzed FBS, plus antibiotics. The cells were washed twice with Hank's balanced salt solution (HBSS), and incubated with Fluo-4-AM $(4 \mu \mathrm{M})$ and Pluronic F127 (0.4\%) for 25 minutes at room temperature. The cells were then washed twice with HBSS, and left at room temperature $(30 \mathrm{~min})$ for de-esterification. Dishes were mounted on an Olympus IX81 microscope and fluorescence changes $\left(\lambda_{\mathrm{ex}}=488 \mathrm{nM},\left(\lambda_{\mathrm{em}}=513 \pm 15 \mathrm{~nm}\right.\right.$ bandpass $)$ monitored using a Yogokawa spinning disk confocal (CSU-X-M1N) and an Andor iXon Ultra 888 EMCCD camera. HEK293 cell lines were sourced from ATCC (CRL-1573) and found to be negative for mycoplasma contamination.

Wire myography. Swiss Webster mice (female, aged 10-13 weeks) were obtained from Charles River Laboratories. Measurements of mouse mesenteric vessel tone were made using a multimyograph system (DMT, Aarhus, Denmark). Vessel strips were isolated from second order mesenteries and equilibrated for $\geq 30 \mathrm{~min}$ in gassed $\left(95 \% \mathrm{O}_{2}, 5 \% \mathrm{CO}_{2}\right)$, physiological saline solution (PSS, $130 \mathrm{mM} \mathrm{NaCl}$, $4.7 \mathrm{mM} \mathrm{KCl}, 1.18 \mathrm{mM} \mathrm{KH}_{2} \mathrm{PO}_{4}, 1.17 \mathrm{mM} \mathrm{MgSO}_{4}, 14.9 \mathrm{mM} \mathrm{NaHCO}_{3}, 5.5 \mathrm{mM}$ dextrose, $0.026 \mathrm{mM}$ EDTA, $1.6 \mathrm{mM} \mathrm{CaCl}_{2}, \mathrm{pH} 7.4$ at $37^{\circ} \mathrm{C}$ ). To identify the optimal pre-stretch value for experiments, a normalization factor $\left(\mathrm{IC}_{1} / \mathrm{IC}_{100}\right)$ was calculated for individual test strips ${ }^{34,35}$, defined as the ratio of the internal circumference at which the maximum response to vasoconstriction (KCl, plus $40 \mu \mathrm{M}$ norepinephrine) was observed $\left(\mathrm{IC}_{1}\right)$, divided by the internal circumference at which a transmural wall pressure of $100 \mathrm{~mm}$ of $\mathrm{Hg}$ is attained on a length-tension plot overlayed with a La Place transformation isobar $\left(\mathrm{IC}_{100}\right)$. After vessel equilibration, reactivity was measured under isometric conditions in response to $\mathrm{KCl}$ (KPSS, $74.7 \mathrm{mM} \mathrm{NaCl}, 60 \mathrm{mM} \mathrm{KCl}, 1.18 \mathrm{mM} \mathrm{KH}_{2} \mathrm{PO}_{4}, 1.17 \mathrm{mM} \mathrm{MgSO}_{4}, 14.9 \mathrm{mM}$ $\mathrm{NaHCO}_{3}, 5.5 \mathrm{mM}$ dextrose, $0.026 \mathrm{mM}$ EDTA, $1.6 \mathrm{mM} \mathrm{CaCl}_{2}, \mathrm{pH} 7.4$ at $37^{\circ} \mathrm{C}$ ) or indicated ligands, as per published protocols. All animal experiments followed ethical regulations approved by the University of Minnesota IACUC committee and reviewed by the National Institutes of Health (NIAID).

Adult Schistosoma mansoni mobility assays. Infected mice were provided by the Biomedical Research Institute (33) from which adult worms were collected by portal perfusion 6-8-week-post infection. Mobility experiments were conducted 24-48 h after worm collection using a compound microscope equipped with a digital video camera to acquire video recordings ( 3 frames per second for $1-2 \mathrm{~min}$ ) of worms exposed to various drugs. Analysis was performed in ImageJ after file import using the Bio-Formats plugin. Differences in illumination were corrected using the stack deflicker function of the wrMTrck plugin. Images were processed by converting to binary format, and mobility was assayed by measuring the average difference in pixels resulting from subtracting two consecutive frames, providing a measurement of the worms displacement over that period $(\sim 0.3 \mathrm{~s})$. This calculation was performed for each frame in the video, and the results were averaged over the length of the recording to provide a metric of worm movement. Unless otherwise noted, values reported represent the mean \pm standard error of at least three independent experiments.

Mammalian GPCR profiling. Primary GPCR screening assays were coordinated through the NIMH Psychoactive Drug Screening Program (PDSP). Methods and statistical analyzes for radioligand binding and functional assays are available in the PDSP Assay Protocol Book available online (https://pdspdb.unc.edu/pdspWeb/). $\mathrm{Ca}^{2+}$ flux assays were performed as similarly described, except experiments utilized muscarinic M1, M3, M5 receptors stably expressed in $\mathrm{CHO}$ cells. For experiments measuring cAMP, experiments utilized co-transfection with the cAMP splitluciferase reporter GloSenso(R)-22F plasmid (Promega, 1:1 ratio with receptor) and were read for luminescence on a TriLux Microbeta (Perkin Elmer). For Gi/o mediated cAMP inhibition, forskolin $(1 \mu \mathrm{M})$ was used to stimulate cAMP via adenylyl cyclase activation.

NFAT reporter assay. The $\mathrm{Ca}^{2+}$ sensitive transcriptional luciferase reporter pGL4.30[luc2P/NFAT-RE/Hygro] (Promega, E8481) was transiently transfected into the $5 \mathrm{HT}_{2 \mathrm{~B}} \mathrm{R}$ stable cell line. Briefly, $3 \times 10^{6}$ cells were plated in a Nunc Cell Culture Treated flask $\left(25 \mathrm{~cm}^{2}\right.$, ThermoFisher $)$ and transfected with lipofectamine 2000 (ThermoFisher) plus $1 \mu \mathrm{g}$ of plasmid DNA according to the manufacturer's protocol. The following day, culture media was replaced with induction media (DMEM $+10 \%$ dialyzed FBS supplemented with $1 \mu \mathrm{g} / \mathrm{ml}$ doxycycline), and $24 \mathrm{~h}$ later cells were re-plated into 96 well, solid white plates (Costar, 3917). After allowing $3 \mathrm{~h}$ for cells to adhere, drugs were added at $20 \times$ concentration. For antagonist experiments, cells were incubated with $5 \mathrm{HT}_{2 \mathrm{~B}} \mathrm{R}$ antagonists for $2 \mathrm{~h}$ prior to subsequent addition of agonist. After $18 \mathrm{~h}$ culture in the presence of agonist, plates were assayed using the ONE-Glo Luciferase Assay System (Promega, E6120) and read on a GloMax-Multi Detection System plate reader (Promega).

Statistical analysis. Except for the myography experiments, data (PDSP data, confocal calcium imaging) were analyzed using the two tailed Student's $t$-test, and are reported except where explicitly indicated as mean \pm s.e.m for independent biological replicates (defined as independent transfections or inductions). For myography experiments, where the amounts of resolved enantiomers were limiting, measurements were made in vessels isolated from 3-6 mice, a sample size 
providing a $\alpha$-significance criterion of 0.05 and a $\beta$ of 0.9 . No randomization or blinding was used in the animal studies, as no comparative analyzes were involved. The statistical significance between experimental groups in myography experiments was determined using the Mann-Whitney test and data are presented as mean \pm s.d. for these assays. Replicate numbers for individual experiments are outlined within Figure Legends or Figures as appropriate for clarity. Probability values of $p<0.05$ were considered statistically significant.

Data availability. The authors declare that the data supporting the findings of this study are available within the paper and its Supplementary Data Files or from the corresponding author on reasonable request.

Received: 17 May 2017 Accepted: 6 November 2017

Published online: 05 December 2017

\section{References}

1. Hotez, P. J. et al. Helminth infections: the great neglected tropical diseases. J. Clin. Invest. 118, 1311-1321 (2008).

2. Ross, A. G. P. et al. Schistosomiasis. NEJM 346, 1212-1220 (2002)

3. Wilson, R. A. \& Coulson, P. S. Schistosoma mansoni: dynamics of migration through the vascular system of the mouse. Parasitology 92, 83-100 (1986).

4. Hotez, P. J. \& Fenwick, A. Schistosomiasis in Africa: an emerging tragedy in our new global health decade. PLoS Negl. Trop. Dis. 3, e485 (2009).

5. Hotez, P. J., Engels, D., Fenwick, A. \& Savioli, L. Africa is desperate for praziquantel. Lancet 376, 496-498 (2010).

6. Doenhoff, M. J. et al. Praziquantel: its use in control of schistosomiasis in subSaharan Africa and current research needs. Parasitology 136, 1825-1835 (2009).

7. Melman, S. D. et al. Reduced susceptibility to praziquantel among naturally occurring Kenyan isolates of Schistosoma mansoni. PLoS Negl. Trop. Dis. 3, e504 (2009).

8. Bergquist, R., Utzinger, J. \& Keiser, J. Controlling schistosomiasis with praziquantel: How much longer without a viable alternative? Infect. Dis. Poverty 6, 74 (2017)

9. Chan, J. D. et al. Ergot alkaloids (Re)generate new leads as antiparasitics. PLoS Negl. Trop. Dis. 9, e0004063 (2015).

10. Bottegoni, G., Kufareva, I., Totrov, M. \& Abagyan, R. Four-dimensional docking: a fast and accurate account of discrete receptor flexibility in ligand docking. J. Med. Chem. 52, 397-406 (2009).

11. Kufareva, I., Ilatovskiy, A. V. \& Abagyan, R. Pocketome: an encyclopedia of small-molecule binding sites in 4D. Nucleic Acids Res. 40, D535-540 (2012).

12. Roth, B. L. et al. Salvinorin A: a potent naturally occurring nonnitrogenous kappa opioid selective agonist. Proc. Natl Acad. Sci. USA 99, 11934-11939 (2002).

13. Woelfle, M. et al. Resolution of praziquantel. PLoS Negl. Trop. Dis. 5, e1260 (2011).

14. Chubb, J. M., Bennett, J. L., Akera, T. \& Brody, T. M. Effects of praziquantel, a new anthelmintic, on electromechanical properties of isolated rat atria. $J$. Pharmacol. Exp. Ther. 207, 284-293 (1978).

15. Jim, K. \& Triggle, D. J. Actions of praziquantel and 1-methyladenine in guineaPig Ileal longitudinal muscle. Can. J. Physiol. Pharmacol. 57, 1460-1462 (1979).

16. Meyer, T. et al. Taste, a new incentive to switch to (R)-praziquantel in schistosomiasis treatment. PLoS Negl. Trop. Dis. 3, e357 (2009).

17. Zamanian, M. et al. The repertoire of $\mathrm{G}$ protein-coupled receptors in the human parasite Schistosoma mansoni and the model organism Schmidtea mediterranea. BMC Genom. 12, 596 (2011).

18. Chan, J. D. et al. A miniaturized screen of a Schistosoma mansoni serotonergic $G$ protein-coupled receptor identifies novel classes of parasite-selective inhibitors. PLoS Pathog. 12, e1005651 (2016).

19. Angelucci, F. et al. The anti-schistosomal drug praziquantel is an adenosine antagonist. Parasitology 134, 1215-1221 (2007).

20. Meister, I. et al. Activity of praziquantel enantiomers and main metabolites against Schistosoma mansoni. Antimicrob. Agents Chemother. 58, 5466-5472 (2014).

21. Buttle, G. A. \& Khayyal, M. T. Rapid hepatic shift of worms in mice infected with Schistosoma mansoni after a single injection of tartar emetic. Nature 194, 780-781 (1962)

22. Vanhoutte, P. M. Serotonin and the vascular wall. Int. J. Cardiol. 14, 189-203 (1987).

23. Watts, S. W., Morrison, S. F., Davis, R. P. \& Barman, S. M. Serotonin and blood pressure regulation. Pharmacol. Rev. 64, 359-388 (2012).

24. Olliaro, P., Delgado-Romero, P. \& Keiser, J. The little we know about the pharmacokinetics and pharmacodynamics of praziquantel (racemate and R-enantiomer). J. Antimicrob. Chemother. 69, 863-870 (2014).
25. Botros, S. S., El-Din, S. H., El-Lakkany, N. M., Sabra, A. N. \& Ebeid, F. A. Drugmetabolizing enzymes and praziquantel bioavailability in mice harboring Schistosoma mansoni isolates of different drug susceptibilities. J. Parasitol. 92 1344-1349 (2006).

26. Silva, C. L., Morel, N., Lenzi, H. L. \& Noel, F. Increased reactivity to 5hydroxytryptamine of portal veins from mice infected with Schistosoma mansoni. Comp. Biochem. Physiol. A. Mol. Integr. Physiol. 120, 417-423 (1998).

27. Sarin, S. K., Mosca, P., Sabba, C. \& Groszmann, R. J. Hyperdynamic circulation in a chronic murine schistosomiasis model of portal hypertension. Hepatology 13, 581-584 (1991).

28. Ebrahimkhani, M. R. et al. Stimulating healthy tissue regeneration by targeting the 5-HT(2)B receptor in chronic liver disease. Nat. Med. 17, 1668-1673 (2011).

29. Anthony, B., Allen, J. T., Li, Y. S. \& McManus, D. P. Hepatic stellate cells and parasite-induced liver fibrosis. Parasites Vectors 3, 60 (2010).

30. Wacker, D. et al. Crystal structure of an LSD-bound human serotonin receptor. Cell 168, 377-389 (2017). e312.

31. Chen, Y. C., Totrov, M. \& Abagyan, R. Docking to multiple pockets or ligand fields for screening, activity prediction and scaffold hopping. Future Med. Chem. 6, 1741-1755 (2014).

32. Totrov, M. Atomic property fields: generalized 3D pharmacophoric potential for automated ligand superposition, pharmacophore elucidation and 3D QSAR. Chem. Biol. Drug Des. 71, 15-27 (2008).

33. Gaulton, A. et al. The ChEMBL database in 2017. Nucleic Acids Res. 45, D945-D954 (2017).

34. Halpern, W. \& Mulvany, M. J. Tension responses to small length changes of vascular smooth muscle cells [proceedings]. J. Physiol. 265, 21P-23P (1977).

35. Warshaw, D. M., Mulvany, M. J. \& Halpern, W. Mechanical and morphological properties of arterial resistance vessels in young and old spontaneously hypertensive rats. Circ. Res. 45, 250-259 (1979).

\section{Acknowledgements}

Schistosome-infected mice were provided by the NIAID Schistosomiasis Resource Center at the Biomedical Research Institute (Rockville, MD) through NIH-NIAID Contract HHSN272201000005I for distribution through BEI Resources. Work was supported by the NIH (GM088790, R21AI25821, R21AI130642 to J.S.M.; RO1MH61887 to J.D.M. and B.L.R.; R01AI087807 to C.C., T.R.W. and P.M.C.), NSF (MCB1615538 to J.S.M.) and the National Institute of Mental Health's Psychoactive Drug Screening Program PDSP screening program, contract \#HHSN-271-2013-00017-C (NIMH PDSP). We thank Joyce Lee, Nawal Yahya and Jonathan Wojcik for their assistance preparing this work.

\section{Author contributions}

J.D.C, P.M.C., G.S.G., and J.D.M. performed experiments, analyzed data and contributed figures for the manuscript. K.S., T.R.W., P.I.D. performed chemical isolation and validated purity of PZQ enantiomers. Y.Y and R.A. performed in silico modeling analyzes. B. L.R., R.A., C.C., and J.S.M established hypothesis and supervised experimental studies. J. D.C. and J.S.M. co-wrote the manuscript with help from other authors.

\section{Additional information}

Supplementary Information accompanies this paper at https://doi.org/10.1038/s41467017-02084-0.

Competing interests: The authors declare no competing financial interests.

Reprints and permission information is available online at http://npg.nature.com/ reprintsandpermissions/

Publisher's note: Springer Nature remains neutral with regard to jurisdictional claims in published maps and institutional affiliations.

\footnotetext{
Open Access This article is licensed under a Creative Commons Attribution 4.0 International License, which permits use, sharing, adaptation, distribution and reproduction in any medium or format, as long as you give appropriate credit to the original author(s) and the source, provide a link to the Creative Commons license, and indicate if changes were made. The images or other third party material in this article are included in the article's Creative Commons license, unless indicated otherwise in a credit line to the material. If material is not included in the article's Creative Commons license and your intended use is not permitted by statutory regulation or exceeds the permitted use, you will need to obtain permission directly from the copyright holder. To view a copy of this license, visit http://creativecommons.org/ licenses/by/4.0/.
}

(c) The Author(s) 2017 